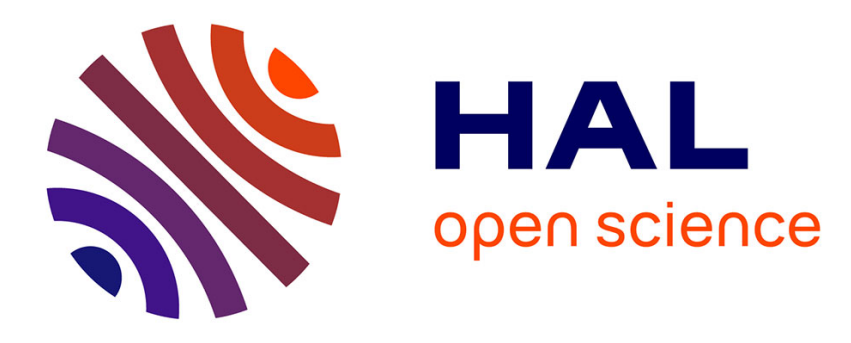

\title{
Perception-Based Advanced Description of Abstract Musical Content.
}

\author{
Olivier Lartillot
}

\section{To cite this version:}

Olivier Lartillot. Perception-Based Advanced Description of Abstract Musical Content.. World Scientific Press; Ebroul Izquierdo. Digital Media Processing for Multimedia Interactive Services, Proceedings of the 4th European Workshop on Image Analysis for Multimedia Interactive Services, pp.320-323, 2003. hal-01161132

\section{HAL Id: hal-01161132 https://hal.science/hal-01161132}

Submitted on 8 Jun 2015

HAL is a multi-disciplinary open access archive for the deposit and dissemination of scientific research documents, whether they are published or not. The documents may come from teaching and research institutions in France or abroad, or from public or private research centers.
L'archive ouverte pluridisciplinaire HAL, est destinée au dépôt et à la diffusion de documents scientifiques de niveau recherche, publiés ou non, émanant des établissements d'enseignement et de recherche français ou étrangers, des laboratoires publics ou privés. 


\title{
PERCEPTION-BASED ADVANCED DESCRIPTION OF ABSTRACT MUSICAL CONTENT
}

\author{
O. LARTILLOT \\ Ircam - Centre Pompidou \\ Place Igor-Stravinsky, \\ 75004 Paris, France \\ E-mail: Olivier.Lartillot@ircam.fr
}

\begin{abstract}
Musical Pattern Discovery aims at inducing pertinent structures within abstract musical description, with the view to developing advanced musical content-based browsing. This paper sketches the general ideas of a new approach that claims to overcome current limitations in this domain, which stem from an insufficient consideration of the perceptual specificity of musical expression. Through an incremental detection of approximate repetitions of patterns, a conceptual network is built on the score.
\end{abstract}

\section{Offering Advanced Description of Musical Content}

\subsection{MIDI: Multimedia Standard for Abstract Musical Content}

Standard MIDI is the most general and natural multimedia format for abstract representation of musical pieces. Indeed, such a format catches the fundamental essence of music as a written language (the score) of symbolic elements (the notes). Such an abstract representation of musical pieces may be performed in different ways (different tempo, different moods, different instruments) by MIDI Players, just like a human musician does. Standard MIDI files are in fact the primary source of music in many popular PC games and CD-ROM entertainment titles, and thousands of MIDI files are available on the Internet for recreational use. Just about every personal computer is now equipped to play Standard MIDI files.

\subsection{A Demand for Music Analysis}

Due to the significant size of MIDI file databases available on Internet, it is necessary, here also, to develop content-based browsing, indexing and retrieval, through the use of advanced descriptors and similarity metrics. This paper is dedicated to the conception of a general advanced description of musical abstract representation that does not rely on any culturally oriented musical theory. Such an automated version of traditional Music Analysis should first of all be able to discover simple musical patterns. For this purpose, a discipline, aimed at this objective of Musical Pattern Discovery, has been constituted. 


\section{Toward Perception-Based Musical Pattern Discovery}

\subsection{Discovering Approximate Repetitions}

Musical patterns may be defined along two main criteria. A pattern may be either a set of notes that are closed together and distant from outer notes, or simply a set of notes that is repeated several time. These correspond to the two main principles of Gestalttheorie: proximity and similarity rules [1]. The first principle may be used for broad segmentation of music into large streams and temporal blocks. However, detailed segmentation of music is better ruled by the second criterion. The trouble is, musical repetitions are not exact, and are therefore not easy to detect. Moreover, music is generally polyphonic, that is: music is not a single line developed along time, but generally a complex flux, that usually cannot even been segregated into voices. For all these reasons, this paper will focus on this important and intricate second criterion of repetition.

\subsection{The Need for Perceptive Heuristics}

Current approaches in Musical Pattern Discovery, importing text or genomebased data mining techniques into the music domain, consider music as a mere sequence of symbols. The trouble is, music is more than a sequence since musical events belong to a temporal metrical space; musical events themselves are more than symbols, since they belong to a pitch metrical space. As music is a human communicative process, pertinent information will be found only through a virtual perception, i.e. a cognitive modelling [2].

\section{General Principles}

\subsection{Incremental Inference of Patterns}

Our experience of music is a chronological progression of partial viewpoints that consists of timely local perception. What are taken into account during music perception are therefore not only the elementary notes, but also local relationships - or local intervals - between note(s) currently perceived and note of the short term past.

Each parameter of each element of local viewpoints - either notes or intervals - may be a characteristic property that, if retrieved later, will recall the considered element. For this purpose, associative memory links elements sharing similar characteristics. Through these similarity links, old elements are 
reactivated by current elements. When degrees of similarity activations exceed certain thresholds, logical similarity relationships are hypothesized and patterns are inferred. Such a modelling of inference through conceptual network shares Holland et al.'s cognitive theory of induction [3].

Once two intervals have been found as similar, their respective following intervals may also be found as equivalent. The succession of two intervals is then considered as a whole construction, a pattern, which can be further extended in a similar and recursive way. In this way, global musical structures are induced from analogical hypotheses on timely local viewpoints.

An abstract pattern is a concept that subsumes a class of similar patterns, which are its occurrences. As patterns are progressively discovered, abstract patterns are represented as chains of states. In this way, an occurrence of a prefix of an abstract pattern is considered as an intermediary occurrence. Two patterns with same prefixes are considered as one single abstract pattern that is linked to two possible extending chains. Therefore, the set of all abstract patterns is a tree: the abstract pattern tree (APT).

Every occurrence of an abstract pattern is implemented as another chain of states, the pattern occurrence chain (POC), which actualizes the interface between the notes in the score and the abstract pattern (see Figure 1). Every state of a POC is linked to its corresponding note in the score, and also to the corresponding state in the corresponding abstract pattern in the APT.



Figure 1. Beethoven's $5^{\text {th }}$ Symphony, beginning: the score, the POCs (black nodes, under the score) and the APT (white nodes, right).

\subsection{Higher-Level Organization}

Now music features higher-level organization between patterns. This structure, not only participating to the global understanding of music, actually influences the recognition of the elementary patterns themselves. In particular, successive occurrences of a same abstract pattern may form a meta-pattern of patterns (see pattern $\mathrm{ABC}$ in Figure 1).

More generally, the notes of the score may belong to multiple patterns of different lengths, where small ones are sometimes included into longer ones.

Such an intertwined relationship between patterns is represented in our framework through an associative relationship network linking abstract patterns. 
More precisely, occurrences of associated patterns are directly linked to abstract patterns. Such an associative relationship between abstract patterns also enables a hierarchic classification of pattern subclasses under abstract pattern classes.

It appears that such algorithm induces non-pertinent knowledge. Then, general cognitive rules have been discovered and added to this framework in order to prevent such bad behaviours. Thanks to this continuous feedback of results to modelling, a pertinent cognitive description has been progressively built.

\section{Prospective}

The algorithm is being implemented as a library called OMkanthuss of an abstract music content processing software called Open Music [4]. Added to the problematic of conception of cognitive modelling is the question of interface and ergonomics. The result of the analysis has to be displayed graphically in a network of relations, above the score itself. Because of its complexity - that cannot be graphically represented and in fact not catchy for human - this network should not be entirely displayed, but only a part of it. The user should be able to navigate inside this network, by choosing temporal objects and hierarchical level of the network.

Musical Pattern Discovery is a first step toward Automated Music Analysis, and, why not, Music Theory Discovery.

\section{Acknowledgments}

This project is carried out in the context of my $\mathrm{PhD}$, supervised by Emmanuel Saint-James (LIP6, Paris VI) and Gérard Assayag (Musical Representations, Ircam). Up-to-date information about the project is available online at following address: www.ircam.fr/equipes/repmus/lartillot.

\section{References}

1. F. Lerdahl and R. Jackendoff, A Generative Theory of Tonal Music. MIT Press (1983).

2. O. Lartillot, LNCS. 2534, 382 (2002).

3. J. Holland, K. Holyoak, R. Nisbeth and P. Thagard, Induction: Processes of Inference, Learning, and Discovery. MIT Press (1989).

4. G. Assayag, C. Rueda, M. Laurson, C. Agon and O. Delerue, Comp. Music J. 23(3), 59 (1999). 